\title{
Understanding linkages between common agricultural policy and High Nature Value (HNV) farmland provision: an empirical analysis in Tuscany Region
}

\author{
Fabio Bartolini ${ }^{* \dagger}$ and Gianluca Brunori ${ }^{\dagger}$
}

\author{
* Correspondence: \\ fabio.bartolini@unipi.it \\ ${ }^{\dagger}$ Equal contributors \\ Department of Agriculture, Food \\ and Environment, University of Pisa, \\ Via del Borghetto 80, 56124 Pisa, Italy
}

\begin{abstract}
The connection between agriculture and environment is a central topic to the agricultural policy agenda and it has been the core of policy reforms. These linkages have been strengthened by the 2003 Common Agricultural Policy (CAP) Reform that has introduced a set of environmental rules as a condition to receive Single Farm Payments (SFP). Consequently, the provision of environmental goods is addressed by both CAP pillars I and II, respectively, with cross-compliance belonging to pillar I while the second axis Rural Development Program (RDP) measures belong to the pillar II. The aim of this paper is to analyse the provision of environmental goods provided by agricultural activities and the impact the Common Agricultural Policy has on such provision. This aim is pursued firstly by quantifying an environmental quality indicator based on the concept of High Nature Value (HNV) farmland and, secondly by testing Exploratory Spatial Data Analysis (ESDA) techniques and spatial econometric models as means to identify provision determinants that improve causality in spatially non-stationary data. The analysis highlights the relevance of spatial models in improving the quality of the estimation, while model results show that rural development program measures and income support payments have opposite effects. Results confirm the relevance of productive factor use and entrepreneurship in explaining differences on environmental quality provision.
\end{abstract}

Keywords: Common agricultural policy; High nature value; Policy impacts; Spatial econometrics; Exploratory Spatial Data Analysis (ESDA); Agri-environmental schemes (AES)

\section{Introduction}

The linkage between agriculture and the environment is central to the agricultural policy agenda (Bureau et al. 2012). Since the introduction of voluntary measures in Regulations 2078/92 and 2080/92, the protection of natural resources and the quality of the environment have been addressed in all agricultural policy reforms and now form the core of the Rural Development Program (RDP) of the European Union. These linkages were strengthened by the 2003 Common Agricultural Policy (CAP) Reform. The provision of environmental goods is addressed by both CAP pillars, cross-compliance belonging to the first pillar and the second axis of RDP measures belonging to the pillar II. Crosscompliance is based on a set of environmental rules as a condition for receiving Single 
Farm Payments (SFPs). Since environmental concerns represent the main justification to maintaining the payments (Hodge 2012), increasing focus has been given to the effectiveness of the environmental measures of the CAP.

One of the main issues is a joint design of agri-environmental schemes (AES) in order to improve the provision of environmental goods (Bartolini et al. 2012). In fact, crosscompliance rules have been set as the baseline for the implementation and quantification of agri-environmental payments, which in turn require additional environmental recommendations (Scheele 2008). As a result, cross-compliance provides an overall minimum environmental quality standard and prevents the fragmentary and uneven provision of environmental goods by AES (Juntti 2012).

Since Agenda 2000, a greater amount of the RDP budget has been allocated to AES in order to encourage farmers to adopt environmentally friendly practices. However, in spite of a relatively high AES budget allocation (about 2.5 billion Euros of EU funds per year), both the scientific literature and policy evaluation reports have reported weaknesses in the design, implementation and evaluation phases of AES (Oréade-Brèche 2005; Purvis et al. 2009). Recently the European Court of Auditors (2011) criticised 1) the low level of targeting of AES, 2) the low linkage between incentive systems and the environmental benefits provided, and 3) the weaknesses of the current evaluation and monitoring systems in measuring environmental benefits and in the additionality measuring.

The objective of this paper is to analyse the provision of environmental goods through agricultural activities and investigate the determinants of this provision, highlighting the relevance of the Common Agricultural Policy. This aim is pursued firstly by quantifying an environmental quality indicator based on the concept of High Nature Value (HNV) farmland and, secondly by testing Exploratory Spatial Data Analysis (ESDA) techniques and spatial econometric models.

Where an HNV farmland indicator is used as a proxy of changes in the maintenance of natural and semi-natural systems, spatial econometric models lead to a better formulation of causality when distribution is affected by spatial heterogeneities and associations (Brady and Irwin 2011). We made an empirical analysis of Tuscany region. The Region has a heterogeneous distribution of habitats (Mücher et al., 2009) and agricultural systems, due to the varying orography, climatic and market conditions. The main novelties of this paper are represented by the HNV index developed for the ex-post analysis of Tuscany and the correction of the results by adding a spatial pattern.

The remaining paper is structured as follows. In the next section the concept of HNV and the indicators applied are reviewed, then the methodology applied is presented and the results are discussed. Finally, in the last section the conclusions of the research are presented.

\section{Background}

\section{Assessing policy impact on the environment}

The impacts of agricultural activities and land-use changes on the environment have been widely studied in the scientific literature. Several authors have documented the agricultural pressure on the loss of biodiversity (Mouysset et al., 2012), nutrient run-off and water quality (Petit and Elbersen, 2006; Leip et al., 2011), soil conservation (Auerswald et al., 2003), and on the landscape (Lefebvre et al., 2014). 
Generally, many studies have shown that low-intensive agriculture is the main source of environmental quality (Foley et al. 2005; Caballero and Gil, 2009) and at the same time is the most vulnerable farming system (Caballero et al., 2008). Thus a set of agricultural policy instruments has been implemented to maintain low-intensive farming and to encourage the shift towards less impacting systems. Policy instruments belonging to both CAP pillars have thus been implemented, consisting mainly of cross-compliance measures and agri-environmental schemes.

A large body of literature deals with the agricultural policy impacts on the environment focusing on both ex-ante and ex-post policy analysis. While the former mainly apply normative or positive mathematical programming models (Louhichi et al., 2010), in the latter environmental impacts are estimated using econometric or statistical models (see Buysse et al., 2007 for a review). These methods quantify the policy changes on the environment using environmental indicators that represent a proxy of impact on the environment (Primdahl et al., 2010; Chiron et al., 2013) or by developing bio-economic models that jointly simulate the agents in an analysis of the impact on the environment and on space (Louhichi et al., 2010).

\section{Application of HNV indicator}

An increasing number of authors have focused on measuring policy impacts by developing indicators that quantify these impacts on multiple dimensions, rather than providing a quantification of a single environmental dimension (Purvis et al., 2009; Primdahl et al., 2010). The current Common Monitoring and Evaluation Framework (CMEF) is based on the quantification of environmental impacts on a set of common indicators. The aim of these indicators is to track policy changes on the main RDP environmental objectives: 1) measuring biodiversity, 2) preserving natural and semi-natural ecosystems, 3) water quality, and 4) combating climate change.

One of these indicators is High Nature Value (HNV) farming and forestry, which quantifies changes in natural and semi-natural ecosystems through a composed index. However, although the HNV farmland index is useful for policy evaluation purposes, it has some weaknesses in accounting for causality between policy intervention and policy effects, in providing evidence of spatial spillover, and in tracking the direct and indirect policy effects highlighted by the scientific literature (Finn et al. 2009).

$\mathrm{HNV}$ is used as a proxy indicator to measure biodiversity and high environmental quality areas across the EU (Paracchini and Britz 2010). The reason for exploiting HNV for monitoring and evaluation, is that it is easier to collect information and to interpret causality between changes in agricultural practices and environmental quality than to use indicators based on the observation of species (Andersen et al. 2003). However, while HNV is a clearly understandable and usable tool for a policy maker to justify measures to promote sustainable agriculture, scientists have been debating about its definition and quantification.

Since the 1990s, the concept of HNV has been used to relate certain farm activities to "a natural value" (Baldock et al. 1993). HNV is a broad concept and includes both HNV farmland areas and HNV farming systems. According to Cooper et al. (2009: pp 4) HNV farmland "comprises those areas in Europe where agriculture is a major (usually the dominant) land use and where that agriculture supports or is associated with either a high 
species and habitat diversity, or the presence of species of European, and/or national, and/ or regional conservation concern, or both". A distinction between HNV farmland areas and HNV forestry is often provided, which is mainly the consequence of the expected benefits from the two HNVs.

HNV farmland has been measured by aggregating three elements (see the European Evaluation Network for Rural Development 2009):

- Farmland with a high proportion of semi-natural vegetation (type 1);

- Farmland with a mosaic of low intensity agriculture and natural and structural elements (type 2);

- A land mosaic or farmland supporting rare species of a high proportion of European or world populations (type 3).

A review of the different ways to measure HNV farmland indicators for monitoring and evaluation purposes can be found in Peppiette (2011). By comparing 24 case studies, Peppiette (2011) shows very heterogeneous definitions and measurements of these indicators as well as a lack of measurements of type 2 and type 3 indicators.

The agricultural and environmental economics literature has identified indicators (or proxies) against which to express or measure a farm contribution to HNV. Table 1 summarises the taxonomy of the HNV indicators and their measurements.

Table 1 shows the indicators used to quantify HNV farmland values. These indicators can be grouped into three approaches; land cover (type 1), farming system (type 2), and species (type 3). For a discussion of these methods, see the European Evaluation Network for Rural Development (2009).

Table 1 Indicators used to measure HNV farmland

\begin{tabular}{|c|c|c|c|}
\hline Component & Indicator & Unit of measure & Sources \\
\hline Type 1 & Farmland area with & (\% of UAA) & Pointereau, et al., (2010); \\
\hline $\begin{array}{l}\text { Land cover } \\
\text { approach }\end{array}$ & $\begin{array}{l}\text { native and old species } \\
\text { and varieties; Forest } \\
\text { Edges }\end{array}$ & $(\%)$ & Pointereau, et al., (2010); \\
\hline \multirow[t]{5}{*}{ Type 2} & $\begin{array}{l}\text { Input per hectare } \\
\text { (nitrogen, water, input } \\
\text { costs) }\end{array}$ & (kgsq m/€ per ha) & \multirow[t]{2}{*}{$\begin{array}{l}\text { Paracchini and Britz, (2010); Pointereau, } \\
\text { et al., (2010); Signorotti et al. (2013); } \\
\text { Pointereau, et al., (2010); Schwaiger } \\
\text { (2012) }\end{array}$} \\
\hline & Farmland mosaic & \multirow{2}{*}{$\begin{array}{l}\text { Plot dimension and ratio } \\
\text { with natural and semi- } \\
\text { natural elements } \\
\text { (hedgerow) }\end{array}$} & \\
\hline & Livestock density - & & $\begin{array}{l}\text { Paracchini and Britz, 2010; Signorotti } \\
\text { et al. (2013); Paracchini and Britz, (2010) }\end{array}$ \\
\hline & & $\begin{array}{l}\text { (livestock units per hectare } \\
\text { of meadows and pastures) }\end{array}$ & \\
\hline & $\begin{array}{l}\text { Presence of extensive } \\
\text { grassland, fallow and } \\
\text { pasture }\end{array}$ & Hectares & Pointereau, et al., (2010); \\
\hline \multirow[t]{3}{*}{ Type 3} & $\begin{array}{l}\text { Shannon index or further } \\
\text { index elaborations }\end{array}$ & \multirow{2}{*}{$\begin{array}{l}\text { Index } \\
\text { (ha of area allocated to. } \\
\text { olive or to wet grassland) }\end{array}$} & $\begin{array}{l}\text { Paracchini and Britz, (2010); Pointereau, } \\
\text { et al., (2010); Paracchini et al., } 2008\end{array}$ \\
\hline & $\begin{array}{l}\text { Presence of specific } \\
\text { crops }\end{array}$ & & $\begin{array}{l}\text { Pointereau, et al., (2010); Patterson } \\
(2012)\end{array}$ \\
\hline & Species data & $\begin{array}{l}\text { (\# of lower plants, vascular } \\
\text { plants, butterflies, mammals } \\
\text { and birds) }\end{array}$ & \\
\hline
\end{tabular}




\section{Policy impacts on HNV farmland changes}

While the literature regarding the definition of indicators that support RDP monitoring and evaluation is well developed, to the best of our knowledge only a few research papers have addressed how the policy impacts on the whole concept of HNV. While several papers quantify policy impacts on specific elements of HNV (e.g. land-use changes, land mosaic, managing intensity, livestock units per hectare), few of them have investigated the policy impacts on the HNV farmland concept as a whole.

Trisorio and Borlizzi (2011) provide a classification of the number of HNV farming systems in Italy, by combining individual data collected by Farm Structure Surveys (FSS) and the Farm Accountancy Data Network (FADN). They identify structural differences between HNV and non-HNV farms; HNV farms are characterised by a smaller size and lower efficiency in production. They further show differences regarding the amount of subsidies received from CAP and observed a higher dependency of HNV farms on RDP payments, while non-HNV farms rely more on pillar I payments. They concluded that subsidies are necessary in order to maintain the economic viability of HNV farms.

Through a spatial Durbin model, Reinhard and Linderhof (2013) estimate the policy effects (mainly payments to AES) on the HNV farmland indicator, and from an analysis at Nomenclature Units Territorial Systems (NUTS) 2 level, they found positive effects of AES on HNV. Signorotti et al. (2013) obtained the same result when applying spatial econometric models to estimate the policy effects on HNV at a municipality level. They found different effects of participation in several AESs and, in particular, involvement in organic farming and landscape measures showed a positive and significant effect, increasing the HNV indicator value, while other AESs implemented were not significant.

Paracchini and Britz (2010) applied an ex-ante analysis of the policy impacts on $\mathrm{HNV}$, and by measuring impacts on alternative CAP policy designs on HNV, they found positive effects of pillar I policy on land-use changes and as a consequence on the quantity and quality of the HNV farmland indicator.

\section{Methods}

\section{Overview}

This section is organized into two parts. The first part develops the quantification of the HNV farmland indicator, while in the second part ESDA and spatial econometrics are used to estimate the determinants of the HNV farmland indicator. We used the approach developed by Paracchini and Britz, (2010), and applied by Reinhard and Linderhof (2013) to study the determinants of the HNV farmland indicator at a regional level, while Signorotti et al., (2013) adopted it for analysis at a municipality level. As previously discussed, the HNV farmland indicator (see Table 1) can be divided into three components, which measure 1) the crop diversity of non-grassland (DCI), 2) the management intensity of non-grassland (MII), and 3) the livestock intensity of grassland (LII) ${ }^{\mathrm{a}}$. Formally, the HNV farmland indicator for a generic municipality $i$ is calculated as follows:

$$
H N V_{i}=100\left(\sqrt{D C I_{i} * M I I_{i}}\left(\frac{\sum_{s \notin G} x_{s}}{\sum_{s} x_{s}}\right)+L I I_{i} \frac{\sum_{s \in G} x_{s}}{\sum_{s} x_{s}}\right)
$$

where: 


$$
\begin{aligned}
& D C I_{i}=\min \left(1,-\sum_{c \forall s \geq 0.1}^{S} a_{n} * \log a_{s}\right) \\
& M I I_{i}=\left\{\begin{array}{ll}
1 & \text { when } n_{i}<P_{5}\left(n_{i}\right) \\
2.25-0.97\left(\log _{10} n_{i}\right) & \text { when } P_{5}\left(n_{i i}\right) \geq n i t_{i} \geq P_{95}\left(n_{i}\right) \\
0 & \text { when } n_{i}>P_{95}\left(n_{i}\right)
\end{array}\right\} \\
& L I I_{i}=\max \left(0,1-0.708 \sqrt{d_{i}}\right) \\
& \sum_{s} x_{s} \text { Usable Agricultural Area (UAA) of a generic municipality } i \\
& \sum_{s \in G} x_{s}=\text { portion of UAA allocated to grassland or fodder crops (set } G \text { ) } \\
& \sum_{s \notin G} x_{s}=\text { portion of the UAA not allocated to grassland or fodder crops } \\
& a_{s}=\text { percentage of UAA allocated to } n \text { crops. } \\
& n_{i}=\text { nitrogen surplus in a generic municipality } i \\
& P_{5}\left(c_{i}\right)=5^{\circ} \text { percentile of nitrogen surplus } \\
& P_{95}\left(c_{i}\right)=95^{\circ} \text { percentile of nitrogen surplus } \\
& d_{i}=\text { livestock units per ha of grassland }
\end{aligned}
$$

The above-mentioned components quantify three different dimensions that together can be considered as a proxy of the HNV system. The three indexes are used to separately evaluate non-grassland crops and grassland crops, due to their different environmental impacts.

Compared with grassland, non-grassland areas (arable areas and orchards) are not considered as a biodiversity source (Paracchini and Britz, 2010). However, when nongrassland areas are managed with low inputs and present semi-natural vegetation or crop diversification, they can impact positively on biodiversity (Paracchini and Britz, 2010; Chiron et al., 2013). On the other hand, when grazing and livestock system are not managed with a low-input use, or there is high livestock intensity on the grassland, there is a reduction in biodiversity and possible negative externalities such as groundwater pollution (Caballero et al., 2007).

Within the first components $(D C I)$, a modified version of the Shannon Index is used to quantify the crop-diversity on non-grassland land. This modified version of the Shannon index returns a non-linear score between zero and one (Paracchini and Britz, 2010) for each municipality.

The second index (MII) measures the intensity of nitrogen used and the index is calculated using a step function. Following Signorotti et al., (2013), for those municipalities within the $95^{\text {th }}$ percentile (higher intensive), the high value of zero is assumed, while for those municipalities within the $5^{\text {th }}$ percentile, a value of one is assumed. For the other municipalities, a non-linear transformation is assumed to return a value close to one when nitrogen is less than $20 \mathrm{~kg}$ per hectare, and close to zero when the value is higher than $190 \mathrm{~kg}$ per hectare. These two threshold values are compatible with the current amount of nitrogen use and are included into the range of restrictions for nitrogen sensitive areas (Bartolini et al., 2007). 
The third index (LII) measures the impacts of grazing and livestock systems on biodiversity, by applying a step function in relation to the livestock intensity in each municipality. The function returns a value of one if livestock intensity in one municipality is close to zero, while it returns zero if the value is higher than two livestock units per ha. The upper boundary represents a set of constraints for nitrogen sensitive areas (Bartolini et al., 2007).

\section{Spatial analysis}

Spatial analysis is a growing topic within the agricultural economics literature (Anselin 2010; Corrado and Fingleton 2012). It enables visual elements to be created within cluster spatial systems, thus permitting the effects of spatial autocorrelation to be studied (Anselin 1995).

We develop the spatial analysis in two steps. Firstly ESDA is used to calculate the distribution of the HNV farmland indicator for each municipality in Tuscany (Italy), and secondly two different spatial econometrics models are used to explain the determinants of the HNV indicator. Generally, in spatial analysis one assumes that spatial autocorrelation can be derived from neighbourhood effects or from distances between observations.

ESDA is a branch of the Exploratory Data Analysis (EDA) which is applied to spatial data (Anselin 1995). It tests spatial distributions and studies spatial stationary phenomena/spatial instability or associated spatial regimes (Anselin 1995).

We use ESDA to identify global and local indicators of spatial association in order to test the existence of spatial autocorrelation between municipalities. These methods are common in regional economics and are being increasingly exploited in agricultural economics (Bell and Dalton 2007; Breustedt and Habermann 2011). Formally a global indicator of spatial correlation is calculated using the global Moran's $I$ (Anselin 1995). The quantification of Moran's I index has the following form:

$$
I=\frac{n}{\sum_{i=1}^{n} \sum_{j=1}^{n} w_{i j}} \frac{\sum_{i=1}^{n} \sum_{j=1}^{n} w_{i j}\left(x_{i}-\bar{x}\right)\left(x_{j}-\bar{x}\right)}{\sum_{i=1}^{n}\left(x_{i}-\bar{x}\right)}
$$

Where:

$w_{i j}$ : Spatial weight, between municipalities $i$ and $j$;

$x_{i}, x_{j}$ : Observed values of variable HNV farmland indicator for municipalities $i$ and $j$;

$\bar{x}$ : Average HNV value;

$n$ : Number of observations (municipalities).

As pointed out by Corrado and Fingleton (2012), any assumption about the spatial weight matrix is fundamental to the specification of spatial phenomena, when measuring the strength and direction of interactions between spatial units (see Mur 2013). Interactions among spatial units are generally hypothesised first by neighbourhood and second by distance. In the first approach, weight matrices are assumed as those spatial units that share part of the border, while in the second approach spatial units are related to each other in terms of distance. We tested the effects of two alternative spatial weight matrices: the order contiguity matrix (queen contiguity) and the inverse distance matrix.

The order contiguity matrix is a binary weight matrix with zeroes on the main diagonal and rows that contain zeroes when spatial units are non-contiguous, while they contain 
values of one between neighbouring units (Mur 2013). The inverse distance matrix is based on the Euclidean distance between centroids of each municipality. Consequently the elements of the matrix measure distances between centroids of the polygons containing municipalities (Mur 2013). Both weight matrices are row normalised, in order to get a value of one as a row sum. Consequently, the two alternative weight assumptions treat spatial association by taking into account neighbourhood or closeness among spatial units, respectively.

Following Anselin (1995), Moran's $I$ is used to calculate a global indicator of spatial association, which, when significant, detects spatial instability and determines unrealistic assumptions regarding spatial stationary data. By decomposing Moran's I, Anselin (1995) developed Local Indicators of Spatial Association (LISA) in order to identify spatial clusters with similar values and to detect spatial outliers with dissimilar values (Anselin, 1995).

The spatial econometrics literature provides several models to control spatial effects in micro-level studies (e.g. Bell and Dalton 2007) and many models are now available (Mur, 2013). Thus, the estimation method chosen is mainly a consequence of data availability and of the expectations regarding the spatial effects of dependent variables (Mur, 2013).

According to LeSage and Pace (2009), the spatial effects can be modelled using a standard linear regression model:

$$
\begin{aligned}
& y_{i}=\rho W_{i} y_{i}+X_{n} \beta+u \\
& u=\lambda W_{i} u+\varepsilon \\
& E\left[\varepsilon_{i}^{2}\right]=\sigma^{2} h\left(z_{i}\right) \\
& E\left[\varepsilon_{i} \varepsilon_{j}\right]=0 \text { with } i \neq j ;
\end{aligned}
$$

Where:

$y$ is $i \times 1$ vector of observations HNV farmland indicator;

$X$ is the $i \times k$ matrix of the $k$ determinants of the HNV farmland indicator;

$\beta$ is the vector of regression parameters (to be estimated);

$\varepsilon$ is the error term;

$W_{i}$ is the $i \times i$ matrix of spatial weights;

$\rho$ and $\lambda$ are the spatial lag parameter and the spatial error coefficient, respectively.

The spatial lag and the spatial error coefficients account for different spatial patterns. The spatial lag quantifies the spatial spillover within the dependent variable; while the spatial error coefficient corrects heteroskedasticity due to spatial dependence in the error term.

According to Breustedt and Habermann (2011), the above set of equations returns different models, based on spatial lag and spatial error coefficient values. Indeed, when $\rho=\lambda=0$ the set of equations equals a standard regression model, otherwise when $\rho \neq 0$ and $\lambda=0$ the equation equals a spatial autoregressive model (SAR) with spatial lag as an explanatory variable of $\mathrm{HNV}$, while when $\rho=0$ and $\lambda \neq 0$ the set of equation equals a spatial error model (SEM) with spatial components as an error term.

The investigation of spatial dependency and spatial heterogeneity has an economic relevance as the HNV farmland indicator is non-stationary over space and due to the spatial agglomeration of stakeholder participation of in agricultural policies. Indeed, natural and semi-natural ecosystems show edge effects (Fernàndez et al., 2002; Conceptión et al., 2012), due to the spatial heterogeneity in farming systems (Dick et al., 2014) and 
due to the spatial heterogeneity of climatic and market conditions (Mücher et al. 2009; Chiron et al., 2013).

Other authors (e.g. Schmidtner et al., 2012) have emphasised the spatial spillover effects of participation in agricultural policies, especially when they are based on voluntary mechanisms such as RDP measures. Thus environmental goods provision is spatially dependent on differences in farm performance or the quality of local institutions and the effects of policy targeting by policy makers (Yang et al., 2014).

\section{Data}

Data from the Italian Agriculture Census 2010 and the ARTEA $^{\mathrm{b}}$ database of pillar I and II CAP payments from the current and previous RDP programs were used in the analysis. Table 2 shows the descriptive statistics of both dependent and explanatory variables.

The first two variables (Table 2) quantify HNV farmland indicators for the years 2010 and 2000. The HNV farmland indicator is quantified using year 2000 Census data and applying the method presented in the previous chapters. A comparison between the two time periods shows an average increase of ca. $10 \%$ in the municipalities in Tuscany.

Explanatory variables can be classified into three categories: farm structure, policy and location. Farm structure variables study the relationships between the characteristics of municipal farming systems, farm management and provision of environmental goods. Variables describing farm structure measuring the productive factors used can affect the farming system intensification/extensification (Bartolini et al., 2011) and thus return different HNV farmland scores. In addition, the characteristics of farmers affect their attitudes towards adopting public goods (Jongeneel et al., 2008). Thus, farming systems with an intensive use of productive factors can have a lower HNV farmland value (Foley et al. 2005).

However, other authors have pointed out a higher efficiency in the marginal productivity of factors used for more intensified farming systems (for example Cohn et al. 2014). This category of variables includes the following variables from Table 2: 1) age (d_old and d_young), 2) the amount of household labour used on the farm (partime), 3) external labour (extlab), 4) legal status (coltdir, condother), 5) farmer living on farm (live_on), 6) average farm size (size), 7) quality products (d_quality), 8) plots (plots) as a proxy of farm efficiency.

The second category contains policy variables, belonging to both CAP pillar I and II. The data used were obtained by aggregating payments received since 2003 under the single payments scheme and from the two RDP programs, namely RDP 2000-2006 and RDP 2007-2013, by the farms located in each municipality. Policy has a prominent role in promoting the provision of HNV farmland (Signorotti et al. 2013; Reinhard and Linderhof 2013). The first pillar policy can negatively affect the HNV farmland score due to maintenance support and the introduction of commodity crops. A negative impact could be balanced by the adoption of cross-compliance commitments on the eligible land (Juntti 2012).

The broader objectives of second pillar measures - increasing productivity, increasing the provision of environmental goods, increasing jobs and the viability of rural areas - can impact on the HNV farmland value (e.g. measures aimed at modernisation can have a negative impact on the HNV farmland value, while increase viabilities of rural areas and payments for introduction and maintenance of environment good positive effects). Hence, 
Table 2 Descriptive statistics of dependent and explanatory variables

\begin{tabular}{|c|c|c|c|c|c|}
\hline Description & Code & Mean & sd & Min & Max \\
\hline HNV at year 2010 & hnv_2010 & 44.72 & 13.57 & - & 84.07 \\
\hline HNV at year 2000 & hnv_2000 & 32.14 & 12.29 & - & 75.26 \\
\hline Share of farmers older than 60 years old & d_old & 39.57 & 11.43 & - & 67.74 \\
\hline Share of farmers younger than 40 years old & d_young & 11.81 & 7.46 & - & 50.00 \\
\hline Share of part time farms (\%) & partime & 33.46 & 14.96 & - & 86.05 \\
\hline Share of farms using external labour (\%) & extlab & 3.69 & 4.52 & - & 37.50 \\
\hline Share of individual farms (\%) & coltdir & 97.98 & 3.02 & 75.00 & 100.00 \\
\hline $\begin{array}{l}\text { Share of farms with legal status different than society } \\
\text { and individual farm (\%) }\end{array}$ & Condoth & 0.33 & 0.80 & - & 7.55 \\
\hline Share of farmers that live on-farm (\%) & live_on & 86.32 & 8.18 & 53.33 & 100.00 \\
\hline Average farm size (ha) & size & 10.86 & 8.53 & 0.65 & 50.98 \\
\hline Share of farms who sell quality products (\%) & d_quality & 13.02 & 14.97 & - & 62.67 \\
\hline Share of farms with only one plot (\%) & Plot & 62.52 & 19.40 & 12.50 & 100.00 \\
\hline Average SFP per ha $(100 €)$ & SFP & 9.79 & 5.02 & - & 35.46 \\
\hline Average RPD -first axis payments per ha $(€)$ & axis1 & 347.86 & 532.06 & - & 3997.56 \\
\hline Average RPD -third axis payments per ha $(€)$ & axis3 & 315.83 & 4102.83 & - & 69244.27 \\
\hline Share of participating in measure 121 (\% of farmers) & rdp_121 & 2.52 & 3.96 & - & 37.50 \\
\hline Sum of compensation payments (In) & comp & 4.09 & 5.67 & - & 14.63 \\
\hline Sum of payments for organic production (In) & org & 9.27 & 4.2 & - & 14.47 \\
\hline Sum of payments for integrated production (In) & int & 10.35 & 3.14 & - & 14.43 \\
\hline Sum of forestry payments (In) & for & 13.69 & 2.09 & - & 16.88 \\
\hline Location in urban area (dummy) & poli_urb & 0.07 & 0.26 & - & 1 \\
\hline Location in intensive agricultural area (dummy) & rur_int & 0.11 & 0.31 & - & 1 \\
\hline Location in rural areas in transition (dummy) & rur_tran & 0.32 & 0.47 & - & 1 \\
\hline Location in declining rural area (dummy) & rur_decl & 0.24 & 0.43 & - & 1 \\
\hline Location in rural area with developing problems (dummy) & rur_probsv & 0.26 & 0.44 & - & 1 \\
\hline UAA classified as Natura2000 sites (ha) & Nat2000 & 9.27 & 4.2 & - & 14.47 \\
\hline UAA classified as Nitrate Vulnerable directive (ha) & $z \vee n$ & 9.27 & 4.2 & - & 14.47 \\
\hline
\end{tabular}

disentangling the impact of second pillar policies can account for the expected multiple impacts on HNV.

Variables using these data were tested: the effects of the intensity of payments (per hectare payments), the logarithmic transformation of the cumulative amount of payments received until 2010. The following variables were used as covariates: SFP per hectare of Usable Agricultural Area, (SFP), the logarithmic transformation of the cumulative sum of payments received from first (axis1) and third RDP axes (axis3); participation in measure 121 , aimed at promoting farm modernisation ( $r d p 121)$, which was one the most relevant measures of the first axis in terms of budget.

The impacts of RDP measures belonging to the second axis were tested using several separate sets of variables by dividing the measures into four groups: 1) compensation payments (measures 211 regarding compensation payments for farms located in less favourable areas, and 212 compensation payments for farms located in mountain areas), 2) organic farming (measure 214, sub-measure A1), 3) integrated production (measure 214, sub-measure A2), and 4) forestry measures (measures 223 afforestation 
of non-agricultural land, 225 forest-environmental payments; 227 non-productive investment in forestry farms). For each group of measures, the logarithmic transformations of cumulative payments received (comp, org, int, for) were used to estimate the policy impacts on HNV.

A further category includes location variables, such as dummies for RDP zoning. This zoning was performed using inhabitant density per municipality and the level of income. The area of Tuscany was classified into five categories (see Tuscany Region 2007 for a definition of the criteria used). Municipalities located inside urban areas belong to the first category, (poli_urb). The second category (rur_int) contains municipalities located in areas whose population density is lower than 300 inhabitants per square kilometre but with very intensive production. The three remaining zones correspond to rural areas characterised by increasing socio-economic concerns, namely rural areas in transition (rur_trans), declining rural areas (rur_decl), and rural areas with development problems (rur_probsv). To identify these additional three categories, variables concerning the share of agricultural labour in the total labour force with respect to the EU 25 average value, were considered in order to identify a declining rural area (rur_decl). Finally rural areas in transition and rural areas with development problems were identified using criteria of urban density less than 150 inhabitants. An additional criterion to distinguish between these two was the amount of tourism in the municipality. Thus municipalities close to urban areas or with tourist attractions (for example in coastal areas) were classified as rural areas in transition (rur_trans), while others were classified as declining rural areas (rur_decl).

Thus different zoning explains the relation between the expectation of off-farm earnings and rural viability. The last zones (rur_decl and rur_probsv) represent marginal municipalities located in hilly or mountain areas and characterised by low incomes compared with the others. In these zones a higher HNV farmland value is expected due to less opportunity for commodity production and low intensive production due to structural and market barriers (Bartolini et al., 2014).

The last category includes the amount of farmland located under Nature 2000 or under nitrogen-vulnerable protection areas (Nat200; $z v n)$. These two zonings are aimed at controlling the inputs for farming activities. They affect crop profitability and thus should have a positive effect on the HNV farmland value.

\section{Results and discussion}

In this section the results of the spatial distribution of HNV are presented, secondly the ESDA analysis is done, for global and local indicators of spatial association, and thirdly, the results of the spatial econometrics models are presented.

The objective of the ESDA is to detect the spatial autocorrelation of the HNV farmland indicator distribution, while the objective of the spatial econometric technique is to estimate HNV farmland indicator determinants, taking into account spatial dependences and spatial heterogeneities (LeSage and Pace, 2009). These analyses are both performed using two alternative spatial weight matrices, namely, first order contiguity and inverse distances.

Figure 1 shows the spatial distribution of HNV municipalities in Tuscany.

Figure 1 presents the HNV farmland indicator for municipalities in Tuscany for 2010 and 2000. The figure containing 2010 values shows a piecemeal distribution of the HNV 


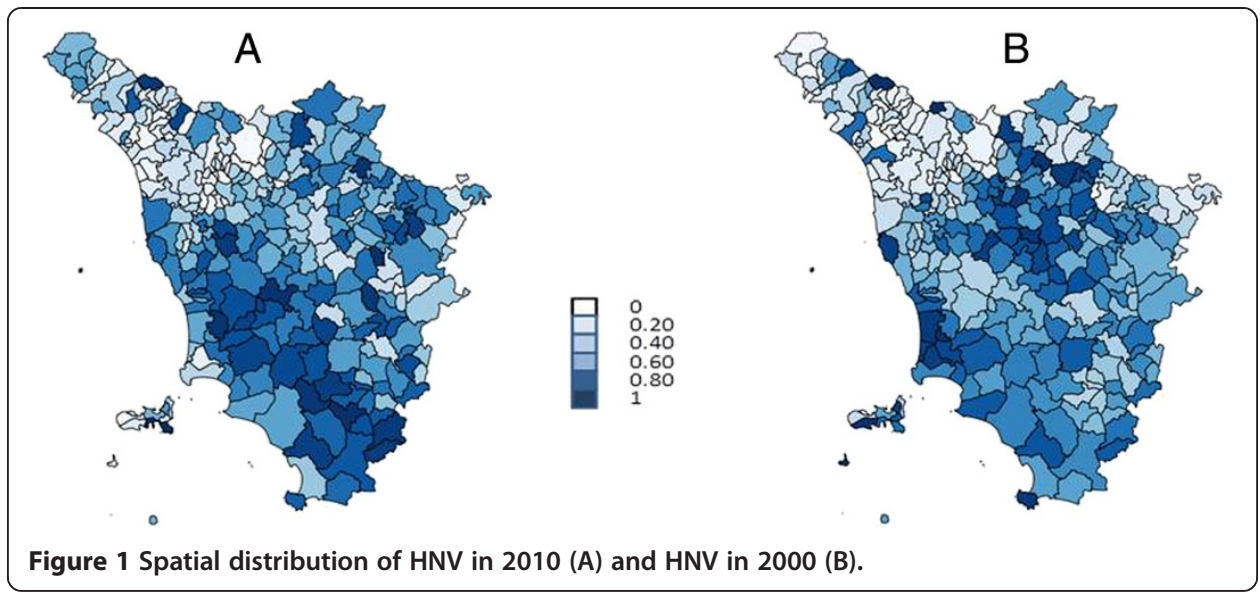

farmland indicator among the municipalities of Tuscany and a clear agglomeration in the south west. The municipalities with a higher HNV performance are mainly located in the provinces of Grosseto, Pisa and Arezzo ${ }^{c}$. High HNV indicator scores were also observed in the north east, but with an uneven distribution among municipalities. Municipalities with high HNV farmland indicators belong to different agricultural production lines with arable farming systems in the south and a combination of livestock and grazing farming systems in the north. In contrast, the intensive agricultural areas located in the provinces of Pistoia, Massa and Florence, show a very low HNV performance, due to the prevailing agricultural system, which is based on floriculture and nursery production. In addition, the map (Figure 1) shows a low HNV farmland indicator value in the mountain areas of Massa and Lucca, due to the relatively high portion of the area allocated to forestry.

The HNV score comparison between years 2010 and 2000 shows an HNV reduction in the central area, as well as in the provinces of Arezzo, Florence and Siena. The comparison highlights small changes in those municipalities with a low HNV score. These municipalities are located in the fluvial planes of the provinces of Lucca, Pisa and Florence.

The ESDA results are shown in Figure 2.

The chart on the left in Figure 2 shows Moran's scatterplot using queen contiguity (A) and the chart on the right uses inverse distances matrix (B). Moran's scatterplot is divided into four quadrants. The one at the top right represents the "hot spots" and the one on the bottom
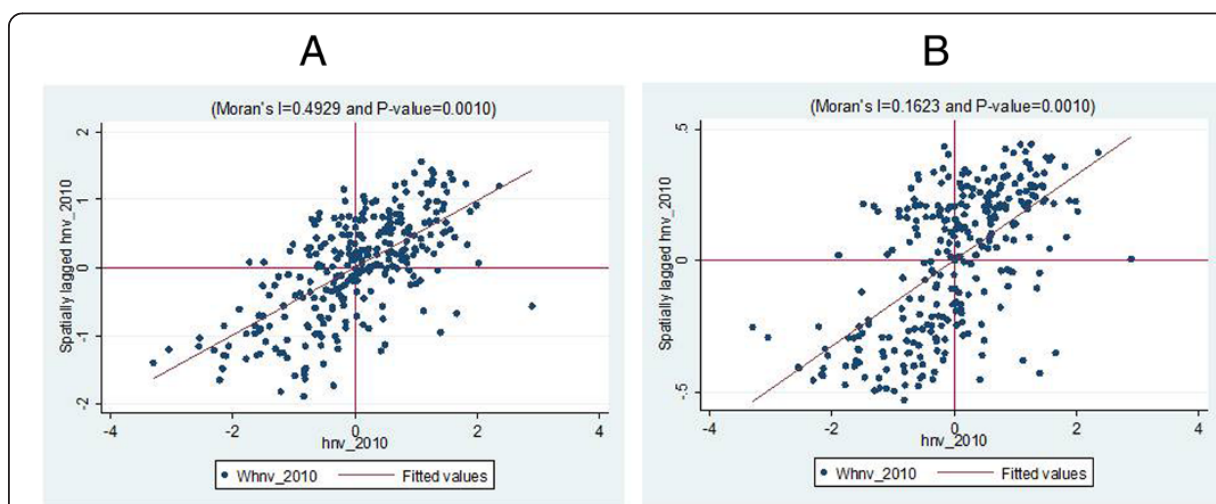

Figure 2 Moran's I indicator for the HNV farmland indicator with different spatial weight matrices.

A) First order contiguity, B) Inverse distances. 
left represents the "cold spots". The line represents the coefficient of Global Moran's I measuring spatial association, which assumes values between -1 and +1 (LeSage and Pace, 2009).

Both the weight matrices result in positive and significant values, which implies that the distribution of HNV is affected by spatial association. The positive and significant values mean that the hypothesis of non-spatial dependency of the observed variables can be rejected, which is the complete spatial random distribution of the HNV farmland indicator. The higher score of Moran's' $I$ using first order contiguity compared with the inverse distance weight matrix shows a higher value of global association ( 0.49 versus 0.19). The results highlight that this weight matrix best describes the pattern of spatial autocorrelation of the HNV distribution. Thus the results highlight that the value of the HNV increases with proximity, but with a different magnitude. Therefore Moran's' I results allow to carry out the spatial analysis.

Figure 3 presents the spatial association (LISA) of the local indicators using alternative spatial weight matrices.

The maps in Figure 3 show the spatial clusters obtained by LISA. The map on the left assumes that spatial effects are driven by contiguity between municipalities, while the map on the right follows the assumption that municipalities are spatially related to each other by the inverse distance matrix. The coloured areas in the map (Figure 3) measure those municipalities that present a statistically significant spatial association. Both Figures 2 and 3 show a "hot spot" cluster (red municipalities), and a "cold spot" cluster (blue municipalities). Figure 3 highlights the extent of the three clusters of local spatial association. The largest cluster, in red (hot spot cluster) is located in the south of the region in the provinces of Grosseto, Siena, Pisa and Livorno. This area shows a high and significant HNV farmland score for the municipalities and for the neighbouring area or close municipalities. The second largest area with a significant local spatial association pattern is the area in the north-west of Tuscany. Here the municipalities show low HNV farmland performances. The municipalities located in the plain represent the most productive area of the region. The third cluster is located in the area between Florence and Arezzo and is characterised by a significantly high HNV farmland value.

The other municipalities highlighted represent spatial outliers, where the spatial unit has a significant and dissimilar value compared to its near-by or neighbouring municipalities. As shown in Figure 3, these spatial outliers area are located in the surrounding area of the two larger clusters.

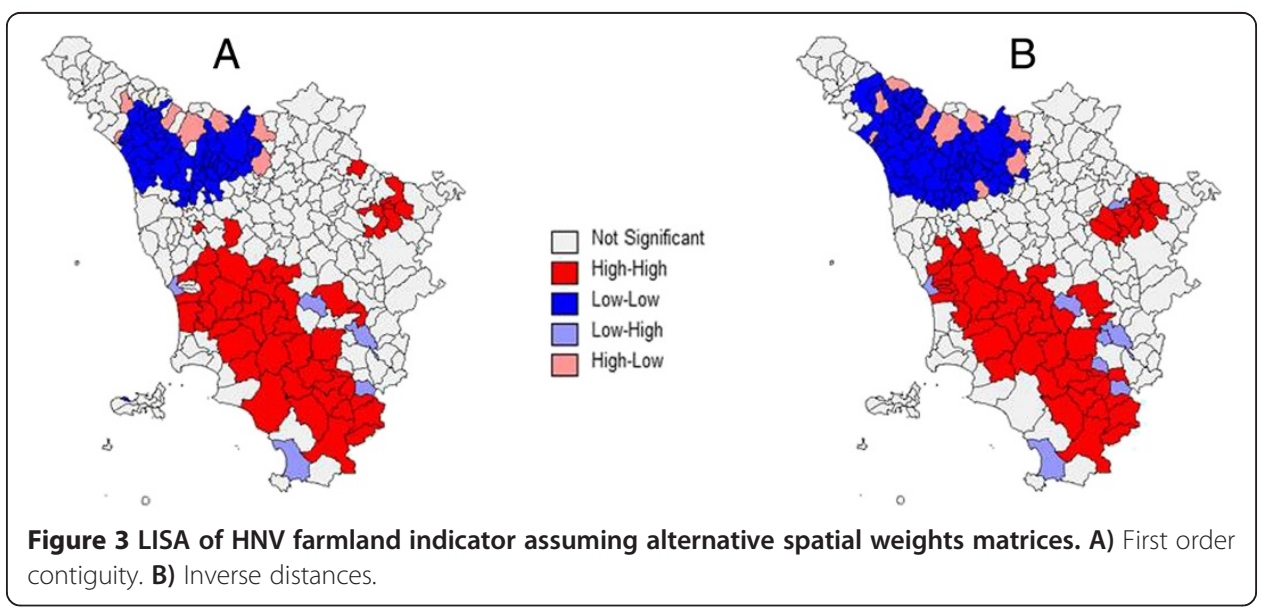


The Table 3 presents the Lagrange Multiplier tests on the ordinary least squares (OLS) residual, while HNV farmland indicator determinants are estimated in Tables 4 and 5 using the two different weight matrices.

The aim of Lagrange multiplier (LM) tests (Table 3) is to compare the OLS model with alternative Spatial Autoregressive (SAR) and Spatial Error (SEM) models, (Table 4), hypothesising the absence of spatial dependence. Results show that assumptions regarding the spatial dependency of HNV are significant for each weight matrix (even with different magnitudes) and the tests suggest the application of both SAR and SEM models (Table 3).

Table 4 presents the OLS, SAR and SEM model results using a spatial weight matrix based on queen contiguity, while Table 5 presents SAR and SEM models using the inverse distance matrix.

The first column in Tables 4 and 5 presents OLS model results (model 1), the second and third columns of Table 4 present the SAR (model 2a) and SEM (model 3a) model results using a first order contiguity matrix, while the second and third columns of Table 5 present SAR (model 2b) and SEM (model 3b) model results using inverse distances matrix.

The OLS model results (Table 4) show that the HNV farmland indicator is positively correlated (0.452) by the value in 2000 ( $\left.h n v_{-} 2000\right)$, suggesting that the provision of HNV increased in those municipalities with a high level of indicator in previous years. This would seem to indicate that environmental quality maintenance has been more effective than the conversion of a new area towards more environmentally sustainable management. Farm structure and the connection between household and external labour influences the HNV farmland indicator, changing the intensity of the productive factors (Trisorio and Borlizzi, 2011). Our results show that when external labour increases (extlab), there is a reduction in the HNV farmland indicator (-0.2603), due to the increased production intensity. In fact, the need to earn enough income to maintain farm household consumption leads to more intensive productive systems compared to areas with a lower level of household labour involved in agriculture. Our results also highlight that with an increasing percentage of part-time farms (partime), there is less efficiency in the use of natural resources and this has a negative impact (-0.0048) on the HNV farmland indicator.

The increase in the average farm size (size), positively affects (0.2319) the HNV farmland value due to an expected higher marginal value of land use by large farming systems.

We found that the share of farmers participating in measure 121 (rdp_121) has a negative effect $(-0.6081)$ on the HNV farmland indicator due to the trade-off between measure 121 objective (farm modernisation) and the environmental measures of axis 2. OLS results show a positive impact (0.7216) of the organic farming payments on the HNV farmland indicator,

Table 3 Diagnostic test for spatial dependence

\begin{tabular}{lcc}
\hline & First order contiguity & Inverse distances \\
\hline LM (spatial error) & $4.358^{* *}$ & 0.081 \\
Robust LM (spatial error) & 2.305 & $2.846^{*}$ \\
LM (spatial autoregressive) & $14.33^{* * *}$ & $9.941^{* * *}$ \\
Robust LM (spatial autoregressive) & $12.277^{* * *}$ & $12.431^{* * *}$ \\
\hline
\end{tabular}

$\left({ }^{* * * *}\right.$ significant at $0.01 ;{ }^{* *}$ significant at $0.05 ;{ }^{*}$ significant at 0.1$)$. 
Table 4 Spatial regression model results using queen contiguity matrix weights

\begin{tabular}{|c|c|c|c|c|}
\hline \multirow[t]{3}{*}{ Variable } & & \multirow{3}{*}{$\begin{array}{l}\text { OLS } \\
\text { Model } 1\end{array}$} & \multicolumn{2}{|c|}{ Queen contiguity } \\
\hline & & & \multirow{2}{*}{$\begin{array}{l}\text { SAR } \\
\text { Model 2a }\end{array}$} & \multirow{2}{*}{$\begin{array}{l}\text { SEM } \\
\text { Model 3a }\end{array}$} \\
\hline & & & & \\
\hline HNV at year 2000 & hnv_2000 & $0.452^{* * *}$ & $0.3893^{* * *}$ & $0.4063^{* * *}$ \\
\hline Share of farmers older than 60 years old & d_old & 0.1059 & 0.0722 & 0.0495 \\
\hline Share of farmers younger than 40 years old & d_young & -0.2021 & -0.1957 & $-0.2922^{*}$ \\
\hline Share of farms using external labour (\%) & extlab & $-0.2603^{* * *}$ & $-0.2053^{* *}$ & $-0.1874^{* *}$ \\
\hline Share of part time farms (\%) & partime & $-0.0048^{* *}$ & -0.0374 & -0.0611 \\
\hline Share of individual farms (\%) & coltdir & 0.1971 & 0.1857 & 0.0905 \\
\hline $\begin{array}{l}\text { Share of farms with legal status different than society and } \\
\text { individual farm (\%) }\end{array}$ & Condoth & $1.1146^{* *}$ & $1.0299 * *$ & $1.228^{* * *}$ \\
\hline Share of farmers that live on-farm (\%) & live_on & -0.0155 & -0.0121 & 0.021 \\
\hline Average farm size (ha) & size & $0.2319^{* * *}$ & $0.1498^{*}$ & 0.1332 \\
\hline Share of farms with only one plot (\%) & Plot & -0.0088 & -0.0029 & -0.0005 \\
\hline Share of farms who sell quality products (\%) & d_quality & 0.0131 & -0.0163 & -0.0067 \\
\hline Average SFP per ha $(100 €)$ & SFP & $-0.2513^{*}$ & $-0.2861^{*}$ & $-0.3933^{* *}$ \\
\hline Average RPD -first axis payments per ha $(€)$ & axis1 & -0.0022 & -0.0014 & -0.0014 \\
\hline Average RPD -third axis payments per ha $(€)$ & axis3 & 0.0015 & 0.0025 & 0.0035 \\
\hline Share of participating in measure 121 (\% of farmers) & rdp_121 & $-0.6081^{*}$ & $-0.5564^{*}$ & $-0.6514^{*}$ \\
\hline Sum of payments for integrated production (In) & Int & 0.4073 & 0.2558 & 0.2625 \\
\hline Sum of payments for organic production (In) & Org & $0.7216^{* * *}$ & $0.5697^{* *}$ & $0.4884^{* *}$ \\
\hline Sum of compensation payments (In) & Comp & 0.0637 & 0.0701 & 0.0812 \\
\hline Sum of forestry payments (In) & For & -0.2786 & -0.2434 & -0.3964 \\
\hline Location in urban area (dummy) & poli_urb & -3.3661 & -0.5402 & -0.3509 \\
\hline Location in intensive agricultural area (dummy) & rur_int & $-6.2800^{* * *}$ & -2.2724 & -3.0717 \\
\hline Location in declining rural area (dummy) & rur_decl & $5.7156^{* * *}$ & $4.205^{* *}$ & $4.4842^{* *}$ \\
\hline Location in rural area with developing problems (dummy) & rur_probsv & $5.3520^{* *}$ & $4.4356^{* *}$ & $5.9949^{* *}$ \\
\hline UAA classified as Natura2000 sites (ha) & nat2000 & 0.0010 & 0.0007 & 0.0005 \\
\hline UAA classified as Nitrate Vulnerable directive (ha) & nvz & $-0.0017^{*}$ & -0.0014 & -0.0015 \\
\hline _cons & & 3.3090 & -5.5711 & 23.8088 \\
\hline rho & & & $0.3866^{* * *}$ & \\
\hline lambda & & & & $0.6804^{* * *}$ \\
\hline $\mathrm{N}$ & & 285 & 285 & 285 \\
\hline r2 & & 0.510 & & \\
\hline r2_a & & 0.481 & 0.585 & 0.510 \\
\hline aic & & 2116.438 & 2099.935 & 2104.245 \\
\hline bic & & 2211.403 & 2202.204 & 2206.515 \\
\hline
\end{tabular}

$\left({ }^{* * *}\right.$ significant at $0.01 ;{ }^{* *}$ significant at $0.05 ;{ }^{*}$ significant at 0.1$)$;

due to the extensification of organic production compared with integrated or conventional systems.

The classification of municipalities according to RDP zoning is significant when explaining the value of the HNV farmland indicator and consequently, there are quite heterogeneous effects among the zones. Rural areas with intensive agriculture (rur_int) negatively affect $(-6.28)$ the performance in terms of $\mathrm{HNV}$, while the location in less productive rural areas (rur_dec and rur_probsv) positively affects (5.7156 and 5.352 
Table 5 Spatial regression model results using inverse distance matrix weights

\begin{tabular}{|c|c|c|c|}
\hline \multirow[t]{3}{*}{ Variable } & & \multicolumn{2}{|c|}{ Inverse distances } \\
\hline & & \multirow{2}{*}{$\begin{array}{l}\text { SAR } \\
\text { Model 2b }\end{array}$} & \multirow{2}{*}{$\begin{array}{l}\text { SEM } \\
\text { Model 3b }\end{array}$} \\
\hline & & & \\
\hline HNV at year 2000 & hnv_2000 & $0.4108^{* * *}$ & $0.444^{* * *}$ \\
\hline Share of farmers older than 60 years old & d_old & 0.102 & 0.1021 \\
\hline Share of farmers younger than 40 years old & d_young & -0.1706 & -0.201 \\
\hline Share of farms using external labour (\%) & extlab & $-0.2324^{* * *}$ & $-0.2546^{* * *}$ \\
\hline Share of part time farms (\%) & partime & -0.0440 & -0.0155 \\
\hline Share of individual farms (\%) & Coltdir & 0.2029 & 0.1885 \\
\hline $\begin{array}{l}\text { Share of farms with legal status different than society and } \\
\text { individual farm (\%) }\end{array}$ & Condoth & $1.0962^{* * *}$ & $1.126^{* * *}$ \\
\hline Share of farmers that live on-farm (\%) & live_on & -0.006 & -0.013 \\
\hline Average farm size (ha) & size & $0.1643^{* *}$ & $0.219^{* *}$ \\
\hline Share of farms with only one plot (\%) & Plot & -0.0043 & -0.0086 \\
\hline Share of farms who sell quality products (\%) & d_quality & -0.0015 & 0.0134 \\
\hline Average SFP per ha $(100 €)$ & SFP & $-0.2903^{*}$ & $-0.267^{*}$ \\
\hline Average RPD -first axis payments per ha (€) & axis1 & -0.0023 & -0.0024 \\
\hline Average RPD -third axis payments per ha $(€)$ & axis3 & 0.0023 & 0.0018 \\
\hline Share of participating in measure 121 (\% of farmers) & rdp_121 & $-0.5146^{*}$ & $-0.6105^{*}$ \\
\hline Sum of payments for integrated production (In) & int & 0.3487 & 0.4 \\
\hline Sum of payments for organic production (In) & org & $0.6510^{* * *}$ & $0.7006^{* * *}$ \\
\hline Sum of compensation payments (In) & comp & 0.1051 & 0.0757 \\
\hline Sum of forestry payments (In) & for & -0.3774 & -0.315 \\
\hline Location in urban area (dummy) & poli_urb & -1.4979 & -3.0733 \\
\hline Location in intensive agricultural area (dummy) & rur_int & $-3.8860^{*}$ & $-5.9831^{* * *}$ \\
\hline Location in declining rural area (dummy) & rur_decl & $4.7889^{* * *}$ & $5.5520^{* * *}$ \\
\hline Location in rural area with developing problems (dummy) & rur_probsv & $5.0807^{* *}$ & $5.3670^{* *}$ \\
\hline UAA classified as Natura2000 sites (ha) & nat2000 & 0.0009 & 0.0010 \\
\hline UAA classified as Nitrate Vulnerable directive (ha) & Nvz & -0.0018 & $-0.0017^{*}$ \\
\hline _cons & & -21.9909 & 5.6722 \\
\hline rho & & $0.673^{* * *}$ & \\
\hline lambda & & & 0.3935 \\
\hline $\mathrm{N}$ & & 285 & 285 \\
\hline 12 & & & \\
\hline r2_a & & 0.569 & 0.553 \\
\hline aic & & 2112.043 & 2120.174 \\
\hline bic & & 2214.313 & 2222.444 \\
\hline
\end{tabular}

$\left({ }^{* * *}\right.$ significant at $0.01 ;{ }^{* *}$ significant at $0.05 ;{ }^{*}$ significant at 0.1$)$.

respectively) the provision of HNV. Results do not show any significant effects of the location in urban areas on the HNV farmland indicator.

The OLS model reveals the negative $(-0.002)$ and significance effect of location on a nitrogen vulnerable area $(n v z)$. The results are somewhat counterintuitive due to the unexpected positive effects of the implementation of nitrogen use restriction. The lack of significance in the spatial models emphasizes the spatial distribution of the nitrogen vulnerable areas in zones with high pressure farming systems. Due to the location in 
plains and locations with a high water availability, there is a diffusion of high intensive production in these areas. Contrary to expectations, an increase in the share of UAA under Natura 2000 sites does not significantly affect the HNV farmland indicator.

All coefficients of determination $-R^{2}$, Akaike's Information Criterion (AIC) and Bayesian Information Criterion (BIC) - show an improvement in the estimation by adding spatial parameters so that, with the exception of model $3 \mathrm{~b}$, spatial dependence $(\rho)$ and spatial heterogeneity coefficients $(\lambda)$ are significant and have a positive value.

Both SAR models (model 2a in Table 4 and $2 \mathrm{~b}$ in Table 5) show positive and significant values of $\rho$, which implies that the HNV farmland indicator is affected by spatial spillover. When other conditions are equal, $\rho$ indicates an increase of $0.43 \%$ (model 2a) and $0.75 \%$ (model 2b) of the HNV farmland indicator, given an increase of one per cent (on average) of HNV among spatially related municipalities.

The SEM model results (model $3 \mathrm{a}$ in Table 4, and 3b in Table 5) show significant values of spatial error coefficient $(\lambda)$ only in one case of contiguity among spatial units (model $2 b$ ).

Both spatial autoregressive models and spatial error models show notable differences in determinants of HNV farmland scores compared with OLS model results. The variables that are spatially distributed, such as part-time and location in a vulnerable nitrogen zone, were not significant in explaining HNV, due to the spatial dependence.

\section{Conclusion}

In this paper we investigated the linkages between agricultural activities and the provision of environmental goods by taking into account spatial interactions among observations (i.e. municipalities). Using $\mathrm{HNV}$ as a proxy to measure the environmental quality, we estimated the Common Agricultural Policy contribution to the introduction and maintenance of environmental quality. The results confirm the feasibility of the analyses for normative purposes given that the analysis can capture the causality among policy, farming practices and the impact on environmental quality.

The results emphasise the relevance of both spatial dependency and spatial heterogeneity and show the influence of spatial spillover in explaining the HNV farmland indicator. Thus, spatial analysis techniques improve the understanding of farmland environmental provision, including spatial spillover and correcting heteroskedasticity in the residual.

Our results show the heterogeneous contribution of agricultural activities on HNV farmland provision in municipalities in Tuscany, with the creation of a large agglomeration area characterised by a high and homogenous provision of environmental quality. We found that farm structure and farmer's entrepreneurship impact on the economic performance and are also relevant in explaining differences in environmental goods provision. Consequently environmental goods provision would seem to be a consequence of the right balance between increasing farm efficiency in the use of productive factors and the level of entrepreneurship. These results confirm previous research findings regarding differences in the efficiency of factor use among areas with varied HNV farmland performances (Trisorio and Borlizzi 2011).

Our results highlight the poor design of the environmental rules on environmentally vulnerable zones. In fact, the location of the farm both in the Natura 2000 area or in the nitrogen vulnerable zone is not significant when explaining a positive value of HNV. Such zones are mainly located in the most productive areas and hence, even after applying environmental rules, these areas show the worst HNV farmland performance. 
The results claim for a coherent definition of the environmental pressure and for the environmental rules to be applied effectively. Our computation of the HNV farmland index refers mainly to the crops and livestock, without including species conservation which constitutes the basis for the design of Natura 2000. Thus more accurate indicators that take these elements into account could have a significant impact on the zoning.

The analysis highlights that the provision of HNV farmland seems to be connected more with the intensity of the activities and with the efficiency of a farm's in using resources, rather than the changing behaviour of farmers as pointed out by Wilson (2001). The results also confirm the dependence on public subsidies for maintaining a viable area with a high nature value.

Pillar I and II policies show opposing impacts on the HNV farmland indicator. Even with the introduction of cross-compliance rules, the amount of SFP received per municipality has a negative effect on the HNV indicator. Our results confirm expectations and previous findings (Signorotti et al. 2013; Reinhard and Linderhof 2013) regarding the positive effects of agri-environmental schemes in promoting the HNV farmland indicator. Despite this, our results highlight that only organic farming positively contributes to the HNV farmland value.

However, we found a controversial impact of SFP and RDP on the HNV farmland indicator. We confirmed previous findings regarding policy impacts on HNV provision. They showed a negative effect on HNV provision by income support and RDP payments within the first axis but, on the other hand, a positive effect of the agri-environmental schemes. The proposal for CAP after 2020 includes a greening measure aimed at encouraging crop diversification and the maintenance of natural and semi-natural grasslands. This measure could shift income support payments toward more environmentally sustainable productions and as a consequence reduce the negative impact of SFP on environmental quality.

We found that there is a trade-off within RDP measures when pursuing several RDP objectives. This result is somewhat surprising in this context, and reflects a trade-off between RDP objectives: increasing productivity and farm modernisation (axis one of RDP) on the one hand and improving and maintaining environmental quality (axis two of RDP) on the other. At the same time, there is a need for better coherence in the design and implementation of RDP programs among the several RDP axis and with pillar I policy. Thus, the development of a comprehensive RPD program based on overall regional and territorial strategies seems to be a priority within the new programming.

The paper has some weaknesses in terms of the selection and quantification of the HNV farmland indicator and the modelling components. A lack of data on the micro elements of environmental quality, for example the length/surface of hedgerows or landscape, and plot size, reduced the possibility to include further relevant variables to the HNV dimension (landscape, land mosaic, etc.).

Similarly the lack of data on the quality of forestry at a municipality level meant that forestry elements were excluded from the HNV, which in the context of Tuscany, involves a large portion of the total agroforestry area. Moreover, the HNV farmland indicator is quantified without including forestry farmers. The computation of the HNV farmland indicator only applies for farmers with UAA (and thus in the case of forestry farmers with a portion of forest this is excluded by the analysis). Thus, one of the limitations concerns the lack of forestry contribution to the HNV and thus a "pure" HNV indicator could not be developed. 
The econometrics model was created using a static model, and adding a past HNV indicator as an explanatory variable. However, future work will involve a dynamic analysis, with the use of a dynamic model or working on the changes between the two time periods, in order to better understand the dynamics and policy effects on HNV, by developing space-temporal models.

\section{Endnotes}

${ }^{\mathrm{a}}$ In this paper we focused on developing the HNV farmland index and have not pursued the quantification of forests and semi-natural areas on HNV. This exclusion is due to the lack of data a municipality level regarding the quality of forests. Thus all data refer to farms with UAA different from forests and exclusively forestry farmers were not analysed.

${ }^{\mathrm{b}}$ ARTEA (Agenzia Regionale Toscana per le Erogazioni in Agricoltura) is the agency for agricultural policy payments.

${ }^{\mathrm{c}} \mathrm{A}$ map of the Tuscan Provinces is given in Additional file 1.

\section{Additional file}

Additional file 1: Map of Tuscan Provinces.

Competing interests

The authors declare that they have no competing interests.

Authors' contributions

FB wrote Methods, Results Sections; GB wrote Background; Introduction and Conclusion are common to all authors. All authors read and approved the final manuscript.

\section{Acknowledgements}

The authors wish to thank the three anonymous referees and the Associated Editor for their useful suggestions and comments on the earlier version of the paper.

Received: 26 November 2013 Accepted: 18 July 2014

Published online: 25 October 2014

\section{References}

Andersen E, Baldock D, Bennett H, Beaufoy G, Bignal E, Brouwer F, Elbersen B, Eiden G, Godeschalk F, Jones G, McCracken D, Nieuwenhuizen W, Van Eupen M, Hennekens SGZ (2003) Developing a High Nature Value Farming Area Indicator. IEEP, Copenhagen

Anselin L (1995) Local Indicators of Spatial Association —LISA. Geogr Anal 27(2):93-115, doi:10.1111/j.1538-4632.1995.tb00338.x Anselin L (2010) Thirty years of spatial econometrics. Paper Reg Sci 89(1):3-25, doi:10.1111/j.1435-5957.2010.00279.x

Auerswald K, Kainz M, Fiener P (2003) Soil erosion potential of organic versus conventional farming evaluated by USLE modelling of cropping statistics for agricultural districts in Bavaria. Soil Use Manag 19(4):305-311, doi:10.1111/ j.1475-2743.2003.tb00320.x

Baldock D, Beaufoy G, Bennett G, Clark J (1993) Nature Conservation and New Direction in The Common Agricultural Policy. Institute for European Environmental Policy. Institute for European Environmental Policy, London

Bartolini F, Gallerani V, Raggi M, Viaggi D (2007) Implementing the water framework directive: contract design and the cost of measures to reduce nitrogen pollution from agriculture. Environ Manage 40(4):567-577, doi:10.1007/s00267-005-0136-Z

Bartolini F, Viaggi D, Ronchi D, Gomez Y, Paloma S, Sammeth F (2011) Assessing the Impact of Future CAP Reforms on the Demand of Production Factors, 122nd Seminar EAAE (European Association of Agricultural Economists). Ancona, Italy

Bartolini F, Gallerani V, Raggi M, Viaggi D (2012) Modelling the linkages between cross-compliance and agri-environmental schemes under asymmetric information. J Agr Econ 63(2):310-330, doi:10.1111/j.1477-9552.2012.00339.x

Bartolini F, Andreoli M, Brunori G (2014) Explaining the determinants of on-farm diversification: The case study of Tuscany Region. Bio-base Appl Econ 3(2):137-157, doi:10.13128/BAE-12994

Bell KP, Dalton TJ (2007) Spatial economic analysis in data-rich environments. J Agr Econ 58(3):487-501, doi:10.1111/j.1477-9552.2007.00123.x

Brady M, Irwin E (2011) Accounting for spatial effects in economic models of land use: recent developments and challenges ahead. Environ Res Econ 48(3):487-509, doi:10.1007/s10640-010-9446-6

Breustedt G, Habermann H (2011) The incidence of EU per-hectare payments on farmland rental rates: a spatial econometric analysis of german farm-level data. J Agr Econ 62(1):225-243

Bureau J-C, Tangermann S, Matthews A, Viaggi D, Crombez C, Knops L, Swinnen J (2012) The common agricultural policy after 2013. Intereconomics 47(6):316-342, doi:10.1007/s10272-012-0435-6 
Buysse J, Van Huylenbroeck G, Lauwers L (2007) Normative, positive and econometric mathematical programming as tools for incorporation of multifunctionality in agricultural policy modelling. Agr Ecosyst Environ 120(1):70-81, http://dx.doi.org/10.1016/j.agee.2006.03.035

Caballero R, Gil A (2009) Binding constraints in Castile-La Mancha, Spain's cereal-sheep system. J Sustain Agr 33(1):3-27, doi:10.1080/10440040802394976

Caballero R, Riseth JA, Labba N, Tyran E, Musial W, Molik E, Boltshauser A, Hofstetter P, Gueydon A, Roeder N, Hoffmann H, Moreira MB, Coelho IS, Brito O, Gil A (2007) Comparative typology in six European low-intensity systems of grassland management. Adv Agron 96: doi:10.1016/s0065-2113(07)96001-0

Caballero R, Gil A, Fernández-Santos X (2008) An experts survey on sustainability across twenty-seven extensive European systems of grassland management. Environ Manage 42(2):190-199, doi:10.1007/s00267-008-9134-2

Chiron F, Princé K, Paracchini ML, Bulgheroni C, Jiguet F (2013) Forecasting the potential impacts of CAP-associated land use changes on farmland birds at the national level. Agr Ecosyst Environ 176:17-23, doi:10.1016/j.agee.2013.05.018

Cohn AS, Mosnier A, Havlík P, Valin H, Herrero M, Schmid E, O'Hare M, Obersteiner M (2014) Cattle ranching intensification in Brazil can reduce global greenhouse gas emissions by sparing land from deforestation. Proc Natl Acad Sci doi:10.1073/pnas.1307163111

Conceptión ED, Fernandez-Gonzàlez F, Diaz M (2012) Plant diversity partitioning in Mediterranean croplands: effects of farming intensity, field edge, and landscape context. Ecol Appl 22(3):972-981, doi:10.1890/11-1471.1

Cooper T, Hart K, Baldock D (2009) The Provision of Public Goods Through Agriculture in the European Union. Institute for European Environmental Policy, London

Corrado L, Fingleton B (2012) Where is the economics in spatial econometrics? J Reg Sci 52(2):210-239, doi:10.1111/j.1467-9787.2011.00726.x

Dick J, Maes J, Smith Rl, Paracchini ML, Zulian G (2014) Cross-scale analysis of ecosystem services identified and assessed at local and European level. Ecol Indicat 38:20-30, doi:10.1016/j.ecolind.2013.10.023

European Court of Auditors (2011) Is Agri-Environmental Support Well Designed and Managed? special report 7/2011. Publications Office of the European Union, Luxemburg

European Evaluation Network for Rural Development - EENRD (2009) The Application of the High Nature Value Impact Indicators. European Commission, Brussels

Fernàndez C, Acosta FJ, Abellà G, Lòpez F, Diaz M (2002) Complex edge effect fields as additive processes in patches of ecological systems. Ecol Model 149(3):273-283, doi:10.1016/s0304-3800(01)00464-1

Finn JA, Bartolini F, Bourke D, Kurz I, Viaggi D (2009) Ex post environmental evaluation of agri-environment schemes using experts' judgements and multicriteria analysis. J Environ Plann Manag 52(5):717-737, doi:10.1080/09640560902958438

Foley JA, DeFries R, Asner GP, Barford C, Bonan G, Carpenter SR, Chapin FS, Coe MT, Daily GC, Gibbs HK, Helkowski JH, Holloway T, Howard EA, Kucharik CJ, Monfreda C, Patz JA, Prentice IC, Ramankutty N, Snyder PK (2005) Global consequences of land use. Science 309(5734):570-574, doi:10.1126/science.1111772

Hodge I (2012) Agri-environment policy in an era of lower government expenditure: CAP reform and conservation payments. J Environ Plann Manag 56(2):254-270, doi:10.1080/09640568.2012.664103

Jongeneel RA, Polman NBP, Slangen LHG (2008) Why are Dutch farmers going multifunctional? Land Use Policy 25(1):81-94

Juntti M (2012) Implementing cross compliance for agriculture in the EU: relational agency, power and action in different socio-material contexts. Sociologia Ruralis 52(3):294-310, doi:10.1111/j.1467-9523.2012.00564.x

Lefebvre M, Espinosa M, Gomez y Paloma S, Paracchini ML, Piorr A, Zasada I (2014) Agricultural landscapes as multi-scale public good and the role of the common agricultural policy. J Environ Plann Manag doi:10.1080/09640568.2014.891975

Leip A, Britz W, Weiss F, de Vries W (2011) Farm, land, and soil nitrogen budgets for agriculture in Europe calculated with CAPRI. Environ Pollut 159(11):3243-3253

LeSage JP, Pace RK (2009) Introduction to Spatial Econometrics. Introduction to Spatial Econometrics. Chapman and Hall/CRC, doi:10.1201/9781420064254.ch2

Louhichi K, Kanellopoulos A, Janssen S, Flichman G, Blanco M, Hengsdijk H, Heckelei T, Flichman G, Boisson JM (2010) Bio-economic modelling of soil erosion externalities and policy options: a Tunisian case study. J Bioeconomics 12(2):145-167

Mouysset L, Doyen L, Jiguet F (2012) Different policy scenarios to promote various targets of biodiversity. Ecol Indicat 14(1):209-221, doi:10.1016/j.ecolind.2011.08.012

Mücher CA, Hennekens SM, Bunce RGH, Schaminée JHJ, Schaepman ME (2009) Modelling the spatial distribution of Natura 2000 habitats across Europe. Landsc Urban Plann 92(2):148-159, http://dx.doi.org/10.1016/j. landurbplan.2009.04.003

Mur J (2013) Causality, uncertainty and Identification: three issues on the Spatial econometrics agenda. Italian J Reg Sci 12(1):5-28, doi:10.3280/SCRE2013-001001

Oréade-Brèche (2005) Evaluation des Measures Agro-Environnementales. Oréade-Brèche Auzeville, France

Paracchini ML, Britz W (2010) Quantifying Effects of Changed Farm Practices on Biodiversity In Policy Impact Assessment - An Application of CAPRI-Spat. Institute for Environment and Sustainability of the Joint Research Centre, European Commission

Paracchini M, Petersen J, Hoogeveen Y, Bamps C, Burfield I, van Swaay C (2008) High Nature Value Farmland in Europe. An Estimate of The Distribution Patterns on The Basis of Land Cover And Biodiversity Data, JRC, Scientific and Technical Report

Patterson G (2012) The Development of HNV Forestry Indicators for Scotland. Presentation for Forestry Commission Scotland

Peppiette Z (2011) The Challenge of Environmental Monitoring: The Example of HNV farmland, Paper presented at the 122nd Seminar of European Association of Agricultural Economists, Ancona, Italy, February 17-18, 2011

Petit S, Elbersen B (2006) Assessing the risk of impact of farming intensification on calcareous grasslands in Europe: a quantitative implementation of the MIRABEL framework. Ambio 35(6):297-303, doi:10.1579/06-r-125r.1 
Pointereau P, Doxa A, Coulon F, Jiguet F, Paracchini ML (2010) Analysis of Spatial and Temporal Variations of High Nature Value Farmland and Links With Changes In Bird Populations: A Study On France. Institute for Environment and Sustainability of the Joint Research Centre - European Commission

Primdahl J, Vesterager JP, Finn JA, Vlahos G, Kristensen L, Vejre H (2010) Current use of impact models for agri-environment schemes and potential for improvements of policy design and assessment. J Environ Manage 91(6):1245-1254, doi:10.1016/j.jenvman.2009.12.012

Purvis G, Louwagie G, Northey G, Mortimer S, Park J, Mauchline A, Finn J, Primdahl J, Vejre H, Vesterager JP, Knickel K, Kasperczyk N, Balàzs K, Vlahos G, Christopoulos S, Peltola J (2009) Conceptual development of a harmonised method for tracking change and evaluating policy in the agri-environment: The Agri-environmental Footprint Index. Environ Sci Pol 12(3):321-337, http://dx.doi.org/10.1016/.jenvsci.2009.01.005

Reinhard S, Linderhof V (2013) Report on Data Screening and Qualitative Identification of Causal Relationships., Deliverable D4.5 of the FP7 SPARD project

Scheele M (2008) Common Agricultural Policy: Landscapes Goods and Environmental Services For Rural Areas, Paper presented at the XII Congress of the European Association of Agricultural Economists - Session Brussels, Health Check and future perspectives of the CAP: Challenges for agriculture - A day of scientific dialogue, Brussels 28 August 2008

Schmidtner E, Lippert C, Engler B, Häring AM, Aurbacher J, Dabbert S (2012) Spatial distribution of organic farming in Germany: does neighbourhood matter? Eur Rev Agr Econ 39(4):661-683, doi:10.1093/erae/jbr047

Schwaiger E (2012) The concept of High Nature Value Farmland in Austria - Good practice, Presentation at European Evalutation Network for Rural Development Workshop "High Nature Value Farmland and Forestry". Edinburgh, 20 February 2012

Signorotti C, Marconi V, Raggi M, Viaggi D (2013) How do Agri-Environmental Schemes (AES's) Contribute to High Nature Value (HNV) Farmland: A Case Study in Emilia Romagna, Paper presented at the Second Congress of Italian Association of Agricultural and Applied Economics, Parma, Italy, June 6-7, 2013

Trisorio A, Borlizzi A (2011) Assessing the Impact of Rural Policy on Biodiversity: High Nature Value Farming In Italy, Paper presented at the 122nd Seminar of European Association of Agricultural Economists, Ancona, Italy, February $17-18,2011$

Wilson GA (2001) From productivism to post-productivism ... and back again? Exploring the (un)changed natural and mental landscapes of European agriculture. Trans Inst Br Geogr 26(1):77-102, doi:10.1111/1475-5661.00007

Yang AL, Rounsevell MDA, Wilson RM, Haggett C (2014) Spatial analysis of agri-environmental policy uptake and expenditure in Scotland. J Environ Manage 133(0):104-115, http://dx.doi.org/10.1016/j.jenvman.2013.11.038

doi:10.1186/s40100-014-0013-2

Cite this article as: Bartolini and Brunori: Understanding linkages between common agricultural policy and High Nature Value (HNV) farmland provision: an empirical analysis in Tuscany Region. Agricultural and Food Economics 2014 2:13.

\section{Submit your manuscript to a SpringerOpen ${ }^{\circ}$ journal and benefit from:}

- Convenient online submission

- Rigorous peer review

- Immediate publication on acceptance

- Open access: articles freely available online

- High visibility within the field

- Retaining the copyright to your article

Submit your next manuscript at $\gg$ springeropen.com 